\title{
Antimicrobial Effectiveness of Selected Vranac Wines Against Six Gram-Positive and Six Gram-Negative Bacterial Strains
}

\author{
Aleksandra N Radovanović ${ }^{1}$, Branimir S Jovančičević ${ }^{1}$, Blaga C Radovanović ${ }^{2^{\star}}$ \\ and Tatjana Mihajilov-Krstev ${ }^{2}$ \\ ${ }^{1}$ Faculty of Chemistry, Studentski trg 12-16, 11000 Belgrade, ${ }^{2}$ Faculty of Natural Sciences and Mathematics, Visegradska 33, \\ 18000 Nis, Serbia
}

*For correspondence: Email: blaga_radovanovic@yahoo.co.uk; Tel: +381-18-533015; Fax: +381-18-533-014

Received: 7 March 2013

Revised accepted: 15 March 2014

\begin{abstract}
Purpose: The aim of this study was to assess potential antimicrobial effectiveness of selected red wines from Balkan region, made from autochthonic Vranac V. vinifera $L$. grape variety.

Methods: The antimicrobial activity of Vranac wines against Gram-positive: C. perfringens, B. subtillis,

S. aureus, L. inocua, S. Lutea, and M. flavus and Gram-negative: E. coli, P. aeruginosa, S. enteritidis, $S$. sonnei, K. pneumonia and $P$. vulgaris bacteria stains were studied using the agar well diffusion and micro-well dilution methods. The concentrations of the wine phenolic compounds: gallic acid, caffeic acid, (+)-catechin, resveratrol, quercetin, quercetin-3-glucoside and malvidin-3-glucoside were determined using HPLC analysis.

Results: There was excellent correlation between the contents of gallic acid, caffeic acid, resveratrol, quercetin, quercetin-3-glucoside and malvidine-3-glucoside and the antimicrobial activity of the wines against Gram-positive - C. perfringens and M. flavus (from 0.936 to 0.999) and against Gram-negative bacteria stains - E. coli, P. aeruginosa, S. enteritidis, S. sonnei and P. vulgaris (from 0.904 to 0.999 ). Furthermore, the content of (+)-catechin has good correlation with the antimicrobial activity of the wines only against $L$. inocua and $P$. vulgaris with correlation coefficient of 0.996 and 0.999 , respectively. All selected wine phenolic compounds, however, did not show correlation with antimicrobial activity against K. pneumonia strain.

Conclusion: The antimicrobial activity of selected Vranac wines indicates that some of the wine's phenolic constituents have the potential to inhibit the growth of certain bacterial strains.
\end{abstract}

Keywords: Red wine; Antimicrobial activity; Bacterial strains; Phenolic compounds.

Tropical Journal of Pharmaceutical Research is indexed by Science Citation Index (SciSearch), Scopus, International Pharmaceutical Abstract, Chemical Abstracts, Embase, Index Copernicus, EBSCO, African Index Medicus, JournalSeek, Journal Citation Reports/Science Edition, Directory of Open Access Journals (DOAJ), African Journal Online, Bioline International, Open-J-Gate and Pharmacy Abstracts

\section{INTRODUCTION}

The fact that microorganisms nowadays tend to develop resistance toward drugs, coupled to the undesirable side effects of certain antibiotics offer considerable potentials for the development of new effective antimicrobial agents [1-6]. It is well known that wine grape possesses therapeutically properties, attributed mainly to high polyphenolic content [7-10].
Recent studies indicate that consuming small amounts of red wine on a regular basis reduces the risk of coronary heart disease and arteriosclerosis, and this medical quality is connected to the antioxidant properties of phenolic compounds. Vascular diseases are comparatively rare in France, Portugal, and Italy, but are encountered most frequently in the 
Scandinavian countries and the United Kingdom [11-15].

Moreover, wine polyphenolics manifest a wide range of beneficial health effects, such as antibacterial, antiviral, anti-carcinogenic and antiatherogenic. In many instances, these effects can be attributed to plausible biochemical mechanisms including enhanced apoptosis, growth arrest at one point in the cell cycle, inhibition of DNA synthesis, and modulation of signal transduction pathways by altered expression of key enzymes such as cyclooxygenases and protein kinases activities [4].

The aim of this study was to evaluate the potential antimicrobial effectiveness against: $C$. perfringens, B. subtillis, S. aureus, L. inocua, S. lutea and $M$. flavus Gram-positive and E. coli, $P$. aeruginosa, S. enteritidis, $S$. sonnei, $K$. pneumonia and $P$. vulgaris Gram-negative bacteria strains of selected red wines from Balkan region, made from autochthonic Vranac $V$. vinifera L. grape variety grown in the Serbia and Montenegro.

\section{EXPERIMENTAL}

\section{Chemicals}

Acetonitrile, formic acid (HPLC-grade) and ethanol were obtained from Merck (Darmstadt, Germany); HPLC-grade methanol were purchased from Carlo Erba Reagent (Milan, Italy); gallic acid, (+)-catechin, quercetin, quercetin-3-glucoside, malvidin-3-glucoside and Folin - Ciocalteu`s phenol reagent were supplied from Sigma Chemical Co. (St Louis, Mo, USA); used reagents were of analytical quality.

\section{Wines samples}

Selected Vranac wines from vintage 2009, made from autochthonic Vranac $V$. vinifera $L$. grape variety grown in Balkan region, were provided by different wineries: Plantaža, Podogorica, Montenegro (VW1), Rubin, Kruševac, Serbia (VW2) and Vino Župa, Aleksandrovac, Serbia (VW3).

\section{Determination of total phenolic content}

The concentration of total phenolics in selected Vranac wines was determined by the FolinCiocalteu method described by Singleton and Rossi [16], using an Agilent 8453 UV-visible spectrophotometer (Agilent Technologies, Santa Clara, CA, USA). The concentration was calculated using gallic acid as standard and the results were expressed as $\mathrm{mg}$ of gallic acid equalent/L wine.

\section{High performance liquid chromatography (HPLC) analysis of wine phenolics}

Phenolic compounds contents were determined by using HPLC, by direct injection of each wine sample into an Agilent 1200 chromatographic system - photodiode array detector (DAD) with radiofrequency identification tracking technology for flow cells and fluorescence detector for multiwavelength detection with online acquisition of excitation (Ex) and emission (Em) spectra, and a Chem-Station software. Elution was carried out in gradient mode using two solvent mixtures: (A) formic acid/water $(5: 95 \mathrm{v} / \mathrm{v})$ and (B) acetonitrile/formic acid/water $(80: 5: 15 \mathrm{v} / \mathrm{v})$. The elution profile was as follows: from 0 to $28 \mathrm{~min}$, $0-10.0 \% \mathrm{~B}$, from 28 to $35 \mathrm{~min}, 10-25 \% \mathrm{~B}$, from 35 to $40 \mathrm{~min}, 25-50 \% \mathrm{~B}$, from 40 to $45 \mathrm{~min}, 50$ - $80 \% \mathrm{~B}$, and for last $10 \mathrm{~min}$ again $0 \% \mathrm{~B}$. Aliquots of $5 \mu \mathrm{l}$ were injected into a $4.6 \times 250$ mm RPC-18 column (Zorbax Eclipse XDB-C18) with $5 \mu \mathrm{m}$ particle size. The flow rate was 0.8 $\mathrm{mL} / \mathrm{min}$. The detection wavelengths were 280 , $320,360 \mathrm{~nm}$ for UV, and $275 / 322 \mathrm{~nm}\left(\lambda_{E x} / \lambda_{E m}\right)$ for fluorescence-detection. Identification and quantification of various phenolic compounds were made by using calibration curves obtained with the standard solutions of pure phenolic in the same conditions as the wine samples. The results are expressed in $\mathrm{mg}$ per I of sample (mg/L).

\section{Microorganisms}

The antimicrobial activity of wine samples were tested against a panel which included laboratory control strains obtained from the American Type Culture Collection (Rockville, Md., USA): Six Gram-positive bacteria: Clostridium perfringens ATCC 19404, Bacillus subtillis ATCC 6633, Staphylococcus aureus ATCC 8538, Listeria inocua ATCC 13076, Sarcina lutea ATCC 9341 and Micrococcus flavus ATCC 40240 and six Gram-negative bacteria: Escherichia coli ATCC 25922, Pseudomonas aeruginosa ATCC 9027, Salmonella enteritidis ATCC 13076, Shigella sonnei ATCC 25931, Klebsiella pneumonia ATCC 10031 and Proteus vulgaris ATCC 8427). The strains were grown at $37{ }^{\circ} \mathrm{C}$ for $24 \mathrm{~h}$ on Mueller-Hinton agar (MHA, Torlak, Serbia).

\section{Disc diffusion assay}

Preliminary antimicrobial tests were carried out by disc diffusion method using $100 \mu \mathrm{l}$ of bacterial suspension spread on Mueller-Hinton agar (MHA, Torlak, Serbia) in sterilized Petri dishes (90 $\mathrm{mm}$ in diameter). The discs $(9 \mathrm{~mm}$ in 
diameter, HiMedia Laboratories Pvt LTd, Mumbai, India) were impregnated with $50 \mu$ l of the testing samples and placed on the inoculated agar $(20 \mathrm{ml})$. The inoculated plates were incubated for $24 \mathrm{~h}$ at $37{ }^{0} \mathrm{C}$. Reference antibiotics, Chloramphenicol (30 $\mu \mathrm{g} / \mathrm{disc})$, Streptomycin (30 $\mathrm{\mu g} / \mathrm{disc})$ and Tetracyclin (30 $\mu \mathrm{g} /$ disc) served as a positive control, while the solvent $(10 \%$ ethanol - $50 \mu \mathrm{l} / \mathrm{disc})$ was used as a negative control. It was found that the solvent showed no inhibitory activity. All the tests were performed in triplicate. Antibacterial activity was evaluated by measuring the zone of inhibition (in $\mathrm{mm}$ ) against the test bacterial strains.

\section{Broth microdilution assay}

A broth microdilution method was used to determine the minimum inhibitory concentration (MIC) and minimum bactericidal concentration (MBC) according to the National Committee for Clinical Laboratory Standards (NCCLS, 2003). The inocula of the bacterial strains were prepared from overnight broth cultures and suspensions were adjusted to $0.5 \mathrm{McF}$ arland standard turbidity. A serial doubling dilutions of the testing samples were prepared in a $96 /$ well microtiter plate over the range of $500-0.25 \mu \mathrm{l} / \mathrm{ml}$ in inoculated nutrient broth (the final volume $100 \mu \mathrm{l}$ and the final bacterial concentration was $10^{6} \mathrm{CFU} / \mathrm{ml}$ in each well). The plate was incubated for $24 \mathrm{~h}$ at $37{ }^{\circ} \mathrm{C}$. All experiments were performed in triplicate. Two growth controls consisting of medium with water (negative control) and medium with Chloramphenicol, Streptomycin and Tetracyclin (positive control) were also included. The microbial growth was determined by absorbance at $620 \mathrm{~nm}$ using the universal microplate reader (Thermo Lab systems, Multiskan EX, Software for Multiscan ver. 2.6, Vantos, Finland). MIC was defined as the lowest concentration of test samples at which microorganisms showed no visible growth. In order to determine $\mathrm{MBC}$, broth was taken from each well without visible growth and inoculated on Mueller Hinton agar (MHA) for $24 \mathrm{~h}$ at $37{ }^{\circ} \mathrm{C}$. The MBC is defined as the lowest concentration of the wine samples at which $99.9 \%$ of inoculated microorganisms were killed.

\section{Statistical analysis}

Three analytical replicates were carried out on each sample wine. Measurements were averaged and results are given as mean \pm standard deviation. The standard deviation was calculated by ANOVA using the Minitab statistical package (Minitab Inc, State College, PA, USA).

\section{RESULTS}

All tested Vranac wines exibited antibacterial activity. Inhibition zone diameters against Gram positive: C. perfringens, B. subtillis, $S$. aureus, $L$. inocua, S. Lutea, and M. flavus were $12.0-14.9$ $\mathrm{mm}$ and Gram-negative: E. coli, $P$. aeruginosa, S. enteritidis, S. sonnei, $K$. pneumonia and $P$. vulgaris bacteria stains were 12.1 - $16.8 \mathrm{~mm}$, which is very significant in comparison to the reference antibiotics: chloramphenicol, streptomycin and tetracyclin:

The data in Table 1 show that the antimicrobial activity of investigated Vranac wines was followed: VW1 > WW2 > VW3. All tested Vranac wines show the highest activity against $S$. aureus and S. lutea Gram-positive and against $E$. coli and S. sonnei Gram-negative strains, then the lowest activity against $K$. pneumoniae.

Antibacterial activity of selected red wines was afected by their biochemical composition, expectedly by their phenolic constituents [1-15]. The concentrations of some wine phenolic compounds as well as gallic acid, caffeic acid, (+)-catechin, resveratrol, quercetin, quercetin-3glucoside and malvidin-3-glucoside, determined using HPLC analysis and total phenolic content, determined by UVIVIS spectroscopic analysis are reported in Table 2.

The changes in total phenolic contents and the concentrations of selected phenolic compounds of the wine samples were closely followed with the changes in their antibacterial activity.

The results obtained by microdilution method confirmed disc diffusion results in most cases. Tested red wines showed antimicrobial activity against all tested strains in the range from $62.5-$ $250 \mu \mathrm{L} / \mathrm{mL}$ (Table 3).

\section{DISCUSSION}

The concentrations of wine phenolic compounds can vary significantly within grape cultivars according to environmental conditions of viticulture regions. In addition, during the process of wine preparation, significant changes take place in the composition and content of phenolic compounds, as a result of different winemaking techniques as well as wine fermentation and aging [17-20].

It is reported about the important antimicrobial role played by organic acids in wine, immediately followed by phenolic acids and then by flavonoids [1-16]. Also, antimicrobial efficacy of the wine may be also enhanced by other components of the inherent present in wine, as low $\mathrm{pH}$. 
Table 1: Antimicrobial activities, expressed as diameters of inhibition zone $(\mathrm{mm})$ of selected Vranac wines and referents antibiotics: streptomycin (Strep), tetracycline (Tet) and chloraphenicol (Chlor) against six Gram (+) - and six Gram (-) strains

\begin{tabular}{lcccccc}
\hline Microorganisms & VW1 & VW2 & VW3 & Strep & Tet & Chlor \\
\hline Gram (+) strain & & & & & & \\
C. perfringens & $13.6 \pm 0.2$ & $12.4 \pm 0.5$ & $12.1 \pm 0.9$ & $\mathrm{nt}$ & $29.0 \pm 0.7$ & $\mathrm{nt}$ \\
B. subtillis & $13.8 \pm 0.7$ & $14.2 \pm 0.7$ & $13.5 \pm 0.5$ & $\mathrm{nt}$ & $23.9 \pm 0.9$ & $26.0 \pm 0.8$ \\
S. aureus & $14.5 \pm 0.9$ & $14.9 \pm 0.4$ & $14.2 \pm 0.7$ & $\mathrm{nt}$ & $18.5 \pm 0.3$ & $25.0 \pm 0.4$ \\
L. inocua & $13.0 \pm 0.8$ & $12.9 \pm 0.3$ & $12.0 \pm 0.6$ & $\mathrm{nt}$ & $18.7 \pm 0.2$ & $18.0 \pm 0.9$ \\
S. lutea & $14.4 \pm 0.2$ & $15.2 \pm 0.4$ & $14.5 \pm 0.5$ & $\mathrm{nt}$ & $20.0 \pm 0.2$ & $38.0 \pm 0.8$ \\
M. flavus & $13.4 \pm 0.8$ & $12.7 \pm 0.2$ & $12.3 \pm 0.6$ & $\mathrm{nt}$ & $23.6 \pm 0.7$ & $35.0 \pm 0.6$ \\
Gram (-) strain & & & & & & $\mathrm{nt}$ \\
E.coli & $16.8 \pm 0.8$ & $13.5 \pm 0.9$ & $12.8 \pm 0.5$ & $16.0 \pm 0.4$ & $23.2 \pm 0.2$ & $\mathrm{nt}$ \\
P.aeruginosa & $14.4 \pm 0.3$ & $13.2 \pm 0.8$ & $12.6 \pm 0.6$ & $23.0 \pm 0.7$ & $20.8 \pm 0.5$ & $\mathrm{nt}$ \\
S. enteritidis & $16.0 \pm 0.7$ & $13.6 \pm 0.9$ & $12.2 \pm 0.3$ & $18.0 \pm 0.9$ & $23.3 \pm 0.3$ & $\mathrm{nt}$ \\
S. sonnei & $14.9 \pm 0.5$ & $14.0 \pm 0.8$ & $13.7 \pm 0.6$ & $19.0 \pm 0.8$ & $31.1 \pm 0.8$ & $\mathrm{nt}$ \\
K. pneumoniae & $12.2 \pm 0.2$ & $12.8 \pm 0.9$ & $12.1 \pm 0.2$ & $\mathrm{nt}$ & $23.6 \pm 0.6$ & $\mathrm{nt}$ \\
P.vulgaris & $14.7 \pm 0.4$ & $13.6 \pm 0.3$ & $12.1 \pm 0.2$ & $\mathrm{nt}$ & $19.2 \pm 0.5$ & \\
Notice: the term nt deals with not detected & & & & & &
\end{tabular}

Table 2: Concentrations of phenolic constituents - gallic acid, caffeic acid, (+)-catechin, resveratrol, quercetin and quercetin-3-glucoside - determined by HPLC analysis, and total phenolic content, determined by UV/VIS analysis $(\mathrm{mg} / \mathrm{L})$, of selected Vranac wines

\begin{tabular}{lcccccccc}
\hline $\begin{array}{l}\text { Wine } \\
\text { code }\end{array}$ & Gallic acid & $\begin{array}{c}\text { Caffeic } \\
\text { acid }\end{array}$ & Catechin & Resveratrol & Quercetin & $\begin{array}{c}\text { Quercetin- } \\
\text { 3-glucoside }\end{array}$ & $\begin{array}{c}\text { Malvidin- 3- } \\
\text { glucoside }\end{array}$ & $\begin{array}{c}\text { Total } \\
\text { phenolics }\end{array}$ \\
\hline VW1 & $79.67 \pm 0.47$ & $6.59 \pm 0.91$ & $27.66 \pm 0.13$ & $0.82 \pm 0.12$ & $2.54 \pm 0.12$ & $9.39 \pm 0.32$ & $232.96 \pm 0.12$ & $3710.18 \pm 0.72$ \\
VW2 & $64.33 \pm 0.67$ & $3.03 \pm 0.55$ & $27.61 \pm 0.97$ & $0.55 \pm 0.11$ & $1.47 \pm 0.12$ & $5.36 \pm 0.15$ & $91.35 \pm 0.17$ & $3605.02 \pm 0.27$ \\
VW3 & $47.53 \pm 0.34$ & $2.95 \pm 0.88$ & $18.35 \pm 0.76$ & $0.41 \pm 0.09$ & $1.12 \pm 0.13$ & $2.88 \pm 0.57$ & $53.98 \pm 0.11$ & $3476.10 \pm 0.21$ \\
\hline
\end{tabular}

Table 3: Antimicrobial activity, expressed as $\mathrm{MIC} / \mathrm{MBC}(\mu \mathrm{l} / \mathrm{mL})$ of selected Vranac wines against six Gram (+) and six Gram (-) strains

\begin{tabular}{lllllll}
\hline Microorganism & VW1 & VW2 & VW3 & Strep & Tet & Chlor \\
\hline Gram (+) strain & & & & & & \\
C. perfringens & $125 / 125$ & $125 / 125$ & $125 / 125$ & $\mathrm{nt}$ & $0.9 / 0.9$ & $1 / 8$ \\
B. subtillis & $250 / 250$ & $250 / 250$ & $250 / 250$ & $\mathrm{nt}$ & $0.9 / 0.9$ & $8 / 8$ \\
S. aureus & $125 / 125$ & $125 / 125$ & $125 / 125$ & $\mathrm{nt}$ & $0.12 / 0.9$ & $2 / 16$ \\
L. inocua & $62.5 / 62.5$ & $125 / 125$ & $125 / 125$ & $\mathrm{nt}$ & $0.46 / 0.9$ & $8 / 18$ \\
S. lutea & $125 / 125$ & $250 / 250$ & $125 / 125$ & $\mathrm{nt}$ & $0.06 / 0.06$ & $0.5 / 2$ \\
M. flavus & $125 / 125$ & $125 / 125$ & $125 / 125$ & $\mathrm{nt}$ & $0.4 / 0.9$ & $1 / 1$ \\
Gram (-) strain & & & & & & $\mathrm{nt}$ \\
E.coli & $250 / 250$ & $250 / 250$ & $250 / 250$ & $16 / 16$ & $3.8 / 7.5$ & $\mathrm{nt}$ \\
P.aeruginosa & $125 / 125$ & $250 / 250$ & $125 / 125$ & $8 / 8$ & $7.5 / 7.5$ & $\mathrm{nt}$ \\
S. enteritidis & $125 / 125$ & $250 / 250$ & $250 / 250$ & $4 / 4$ & $0.9 / 1.9$ & $\mathrm{nt}$ \\
S. sonnei & $125 / 125$ & $250 / 250$ & $250 / 250$ & $16 / 16$ & $0.06 / 0.12$ & $\mathrm{nt}$ \\
K. pneumoniae & $125 / 125$ & $250 / 250$ & $250 / 250$ & $\mathrm{nt}$ & $0.9 / 1.9$ & $\mathrm{nt}$ \\
P.vulgaris & $62.5 / 62.5$ & $125 / 125$ & $125 / 125$ & $\mathrm{nt}$ & $1.9 / 1.9$ & \\
\hline
\end{tabular}

In this study, we examined the relative importance of separated wine phenolic components as well as: gallic acid (main and referent component of hydroxybenzoic acids), caffeic acid (main component of hydroxycynnamic acids), (+)-catechin (main and referent component of glavan-3-ols), resveratrol (main component of stilbens), quercetin and quercetin-3-glucoside (main components of flavonols and flavonols glucosides) and malvidin3-glucoside ( main and referent component of anthocyanins) to the antimicrobial activity of same variety wines from Balkan region.
As compared dates presented of Tables 1 and 2, it is clear that VW3 sample, which contained the lowest concentrations of phenolic compounds shows the lowest inhibition zones against all tested bacteria.

In Table 4 are given the correlation coefficients between concentrations of gallic acid, (+)catechin, resveratrol, quercetin, quercetin-3glucoside and malvidin-3-glucoside, determined by HPLC analysis and antimicrobial activity in tested red wine samples. 
Table 4: Correlation coefficients $(r \pm s d+p)$ between concentrations of gallic acid, caffeic acid, $(+)$-catechin, resveratrol, quercetin, quercetin-3-glucoside and malvidine-3-glucoside (mg/L) determined by HPLC-analysis and total phenolic content, determined y UV/VIS with antimicrobial activities $(\mathrm{mm})$ in selected Vranac wines

\begin{tabular}{|c|c|c|c|c|c|c|c|c|}
\hline $\begin{array}{l}\text { Micro- } \\
\text { organisms }\end{array}$ & $\begin{array}{c}r \pm s d+p v s \\
\text { Gallic acid }\end{array}$ & $\begin{array}{l}r \pm s d+p v s \\
\text { Caffeic acid }\end{array}$ & $\begin{array}{c}r \pm s d+p v s \\
\text { Catechin }\end{array}$ & $\begin{array}{l}r \pm s d+p v s \\
\text { Resveratrol }\end{array}$ & $\begin{array}{c}r \pm s d+p v s \\
\text { Quercetin }\end{array}$ & $\begin{array}{c}r \pm s d+p v s \\
\text { Quercetin-3- } \\
\text { glucoside }\end{array}$ & $\begin{array}{c}r \pm s d+p \\
v s \\
\text { Malvidin-3- } \\
\text { glucoside }\end{array}$ & $\begin{array}{c}r \pm s d+p v s \\
\text { Total } \\
\text { phenolics }\end{array}$ \\
\hline \multicolumn{9}{|l|}{ Gram (+) } \\
\hline $\begin{array}{l}\text { C. } \\
\text { perfringens }\end{array}$ & $0.936 \pm 0.395$ & $0.985 \pm 0.191$ & $0.658 \pm 0.845$ & $0.988 \pm 0.170$ & $0.999 \pm 0.055$ & $0.981 \pm 0.219$ & $0.999 \pm 0.010$ & $0.924 \pm 0.428$ \\
\hline B. subtillis & $0.451 \pm 0.443$ & $0.063 \pm 0.495$ & $0.819 \pm 0.284$ & $0.257 \pm 0.479$ & $0.156 \pm 0.491$ & $0.300 \pm 0.473$ & $0.117 \pm 0.493$ & $0.479 \pm 0.435$ \\
\hline S. aureus & $0.451 \pm 0.443$ & $0.063 \pm 0.495$ & $0.819 \pm 0.285$ & $0.257 \pm 0.479$ & $0.156 \pm 0.491$ & $0.300 \pm 0.473$ & $0.116 \pm 0.492$ & $0.479 \pm 0.435$ \\
\hline L. inocua & $0.919 \pm 0.308$ & $0.592 \pm 0.627$ & $0.996 \pm 0.067$ & $0.816 \pm 0.448$ & $0.753 \pm 0.512$ & $0.842 \pm 0.420$ & $0.727 \pm 0.535$ & $0.930 \pm 0.284$ \\
\hline S. lutea & $0.101 \pm 0.614$ & $0.580 \pm 0.502$ & $0.393 \pm 0.566$ & $0.292 \pm 0.589$ & $0.389 \pm 0.567$ & $0.249 \pm 0.597$ & $0.142 \pm 0.557$ & $0.056 \pm 0.615$ \\
\hline M. flavus & $0.983 \pm 0.143$ & $0.940 \pm 0.268$ & $0.781 \pm 0.492$ & $0.999 \pm 0.019$ & $0.992 \pm 0.101$ & $0.999 \pm 0.015$ & $0.986 \pm 0.132$ & $0.977 \pm 0.167$ \\
\hline \multicolumn{9}{|l|}{ Gram (-) } \\
\hline E. coli & $0.927 \pm 1.135$ & $0.989 \pm 0.437$ & $0.639 \pm 2.324$ & $0.984 \pm 0.534$ & $0.997 \pm 0.224$ & $0.975 \pm 0.666$ & $0.999 \pm 1.105$ & $0.914 \pm 1.225$ \\
\hline $\begin{array}{l}P . \\
\text { aeruginosa }\end{array}$ & $0.977 \pm 0.278$ & $0.951 \pm 0.401$ & $0.759 \pm 0.843$ & $0.999 \pm 0.011$ & $0.996 \pm 0.122$ & $0.996 \pm 0.071$ & $0.991 \pm 0.173$ & $0.969 \pm 0.319$ \\
\hline $\begin{array}{l}\text { S. } \\
\text { enteritidis }\end{array}$ & $0.984 \pm 0.478$ & $0.938 \pm 0.941$ & $0.784 \pm 1.687$ & $0.999 \pm 0.082$ & $0.991 \pm 0.363$ & $0.999 \pm 0.038$ & $0.985 \pm 0.469$ & $0.970 \pm 0.564$ \\
\hline S. sonnei & $0.953 \pm 0.267$ & $0.975 \pm 0.195$ & $0.697 \pm 0.633$ & $0.995 \pm 0.088$ & $0.999 \pm 0.003$ & $0.999 \pm 0.127$ & $0.999 \pm 0.038$ & $0.943 \pm 0.294$ \\
\hline & $0.158 \pm 0.528$ & $0.363 \pm 0.498$ & $0.606 \pm 0.425$ & $0.049 \pm 0.534$ & $0.152 \pm 0.529$ & $0.004 \pm 0.535$ & $0.191 \pm 0.525$ & $0.190 \pm 0.525$ \\
\hline \multicolumn{9}{|l|}{ pneumonia } \\
\hline P. vulgaris & $0.904 \pm 0.542$ & $0.829 \pm 1.031$ & $0.999 \pm 0.065$ & $0.964 \pm 0.491$ & $0.730 \pm 0.866$ & $0.823 \pm 0.720$ & $0.916 \pm 0.740$ & $0.999 \pm 0.055$ \\
\hline
\end{tabular}

It was found the excellent correlation coefficients between contents of gallic acid, caffeic acid, resveratrol, quercetin, quercetin-3-glucoside and malvidin-3-glucoside and the antimicrobial activity of wine samples against $C$. perfingens and M. flavus (from 0.936 to 0.999 ) and between contents of gallic acid and $(+)$-catechin against $L$. inocea $(0.919$ - 0.996). Also, contents of gallic acid, caffeic acid, resveratrol, quercetin, quercetin-3-glucoside and malvidin-3-glucoside showed excellent correlation with antimicrobial activity of wine samples against all Gramnegative bacteria stains: $E$. coli, $P$. aeruginosa, $S$. enteritidis, $S$. sonnei and $P$. vulgaris (from 0.904 to 0.999 ), except against $P$. pneumonia. Then, the content of $(+)$-catechin has good correlation with antimicrobial activity of tested wines only against $P$. vulgaris. All selected wine phenolic compounds do not show correlation with the antimicrobial effectiveness against $K$. pneumonia strain.

Total phenolic content of investigated Vranac wines, also shown very good correlation with Gram (-) - bacterial strains: C. perfringens, $L$. inocua and M. flavus (from 0.924 to 0.977 ) and with all Gram (+) - bacterial strains (from 0.914 to 0.999), except against $K$. pneumonia strain.

\section{CONCLUSION}

The concentrations of phenolic compounds are very important for understanding biological potency of red wines. This study confirmed that high levels of phenolic compounds in Vranac wines contribute to their high antimicrobial effectiveness. It can be concluded that the very good correlations exhibited between the contents of some wine phenolic constituents and the antimicrobial activities of Vranac wines against six Gram-positive and six-Gram negative pathogenic bacterial strains. Development of alternative regimen using natural compounds as well as grape/wine phenolic compounds for the prevention and control of infections caused by bacteria resistant to antibiotics is very important for human health.

\section{ACKNOWLEDGEMENTS}

The research was supported by the Europe Union (FP7-Regpot-2007-3-01, KBBE, no. 204756) and by the Ministry of Education and Science of the Serbia, project nos. TR-34012, 031020 and 176006.

\section{REFERENCES}

1. Puupponen-Pimia R, Nohynek L, Alakomi H-L, OksmanCaldentey K-M. Bioactive berry compounds-novel tools against human pathogens Appl Microbiol Biotechnol 2005; 67: 8-18.

2. Papadopoulou C, Soulti K, Roussis IG. Potential antimicrobial activity of red and white wine phenolic extracts against strains of $S$. aureus, E.coli and C.albicans. Food Technol Biotechnol 2005; 43: 4146.

3. Daglia $M$, Papeti A, Grisoli P, Aceti C, Dacarro C, Gazzani G. Antibacterial activity of red and white wine against oral Streptococci. J Agric Food Chem 2007; 55: 5038-5042.

4. Heinonen IM, Meyer AS, Frankel EN. Antioxidant activity of berry phenolics on human low-density lipoprotein 
and liposome oxidation. J Agric Food Chem 1998; 46: 4107-4112.

5. Thimothe J, Bonsi IA, Padilla-Zakour Ol, Koo $\mathrm{H}$. Chemical Characterization of Red Wine Grape (Vitis vinifera and Vitis Interspecific Hybrids) and Pomace Phenolic Extracts and Their Biological Activity against Streptococcus mutans. J Agric Food Chem 2007; 55: 10200-10207.

6. Radovanović A, Radovanović $B$, Jovančičević $B$. Free radical scavenging and antibacterial activities of southern Serbian red wines. Food Chem 2009; 117: 326-333.

7. German J, Walzem RL. The health benefits of wine. Ann Rev Nutr 2000; 20: 561-593.

8. Renaud SC, de Lorgeril M.Wine, alcohol, platelets, and the French paradox for coronary heart disease. Lancet, 1992; 339: 1523-1526.

9. Sugita-Konishi $Y$, Hara-Kudo $Y$, Iwamoto $T$, Kondo $K$. Wine has activity against entero-pathogenic bacteria in vitro but not in vivo. Biosci. Biotechnol. Biochem 2001; 65: 954-957.

10. Soleas GJ, Grass L, Josephy PD, Goldberg DM, Diamandis EP. A comparison of the anticarcinogenic properties of four red wine polyphenols. Clin. Biochem. 2002; 35: 119-124.

11. Carluccio MA, Siculella L, Ancora MA, Massaro $M$, Scoditti E, Storelli C, Visioli F, Distante A, De Caterina $R$. Olive oil and red wine antioxidant polyphenols inhibit endothelial activation: antiatherogenic properties of Mediterranean diet phytochemicals. Arterioscler. Thromb. Vasc. Biol.2003; 23: 622-629.

12. Rodríguez Vaquero MJ, Albert MR, Manca de Nadra MC. Antibacterial effect of phenolic compounds from different wines. Food Control 2007; 18; 93101.

13. Braicu C, Pilecki V, Balacescu O, Irimie A, Neagoe JB. The relations between biological activities and structure of flavan-3-ols. Int J Mol Sci 2011; 12: 9342-9353

14. Havsteen BH. The biochemistry and medical significance of the flavonoids. Pharmacol. Therapeut.2002; 96: 67-202

15. Just JR, Daeschel MA. Antimicrobial effects of wine on Escherichia coli 0157 : H7 and Salmonella typhimurium in a model stomach system. J Food Sci 2003; 68: 285-290.

16. Singleton VL, Rossi JA. Calorimetry of total phenolics with phosphomolybdispho-sphotungstic acid reagents. Am J Enol Vitic 1965; 16: 144-158.

17. McDonald MS, Hunhes M, Burns J, Lean M, Matthews $D$, Crozier $A$. Survey of the free and conjugated myricetin, and quercetin content of red wines of different geographical origin. J Agric Food Chem1998; 46: 368-375

18. .Cliff MA, King MC, Schlosser J. Anthocyanin, phenolic composition and sensory analysis of $B C$ commercial red wines. Food Res Int 2007; 40: 92100.

19. Ginjon I, D'Arcy B, Caffin N, Gidley M. Phenolic compound profiles in selected Queensland red wines at all stages of the wine-making process. Food Chem 2011; 125: 823-834.

20. Tenore GC, Basile A, Novellino E. Antioxidant and antimicrobial properties of polyphenolic fractions from selected Moroccan red wines. J Food Sci 2011; 76: 342-348. 